\title{
Home modifications for older people with cognitive impairments: Mediation analysis of caregivers' information needs and perceptions of fall risks
}

\author{
Heejung Kim PhD, GNP-BC, RN, Assistant Professor ${ }^{1,2}$ (D) | Yunchuan (Lucy) Zhao PhD, \\ MPAff, RN, Assistant Professor ${ }^{3}$ (D) | Namhee Kim MPH, RN, Doctoral Student ${ }^{1}$ (D) | \\ Yong Han Ahn PhD, Associate Professor ${ }^{4}$ (D)
}

${ }^{1}$ College of Nursing, Yonsei University, Seodaemun-gu, Seoul, Korea

${ }^{2}$ Mo-Im Kim Nursing Research Institute, Yonsei University, Seodaemun-gu, Seoul, Korea

${ }^{3}$ School of Nursing, Boise State University, Boise, Idaho

${ }^{4}$ Department of Architecture and Architectural Engineering, Hanyang University-ERICA, Ansan, Sangnok-gu, Korea

\section{Correspondence}

Yong Han Ahn, Department of Architecture and Architectural Engineering, Hanyang University-ERICA, Room \#210, Engineering II, 55 Hanyangdaehak-ro, Sangnok-gu, Ansan, Gyeonggi-do 15588, Korea.

Email:yhahn@hanyang.ac.kr

Funding information

This work was supported by Basic Science Research Program through the National Research Foundation of Korea (NRF) funded by the Ministry of Science, ICT \& Future Planning [grant number 2015R1A5A1037548]. The funder had no role in the design, collection, analysis, interpretation, writing or decision to submit of this article.

\begin{abstract}
Aims and objectives: The aims were to (a) identify how many older people with cognitive impairments are living in modified homes and (b) explore associated factors, and (c) examine the mediating effects that their caregivers' information needs and perceptions of fall risk and other factors.

Background: Older people and their informal caregivers may consider implementing home modifications as an effective strategy for fall prevention. However, there is a lack of information on which older people's homes receive modifications and the various factors associated with such modifications among community-dwelling older people with cognitive impairments.

Design: This cross-sectional and correlational study utilises a secondary data analysis. Methods: The data for this secondary analysis were taken from the 2015 National Online Survey of Caregivers, which includes information provided by 226 adult caregivers for older people with cognitive impairments. Descriptive analyses, hierarchical binary logistic regression and structural equation modelling were performed based on the Andersen and Newman framework of health services utilisation.

Results: Overall, $46.5 \%$ of the older people lived in modified homes. Older people's impaired activities for daily living (ADLs), caregivers' information needs and perceptions of fall risk were all associated with home modifications (all $p$ values<0.05). Caregivers' information needs mediated the relationship between impaired ADLs and home modifications (indirect effect $=0.026, p<0.05$ ), whereas the caregivers' perceptions of fall risk did not.

Conclusions: Older people with both cognitive and functional impairments are more likely to modify their home on behalf of care recipient's staying at home. Caregivers' information needs should thus be prioritized when considering home modifications to facilitate caring for older people with impaired ADLs.

Implication for practice: Nurses and other healthcare professionals should be prepared to offer appropriate information and comprehensive assessments of older people's conditions with regard to home modifications.
\end{abstract}


KEYWORDS

activities of daily living, caregivers, cognitive impairment, falls, homes for the aged, older people

\section{1 | INTRODUCTION}

Falls are a major public health problem. In the United States, every year approximately one-third of those aged 65 or over experience a fall (Centers for Disease Control \& Prevention [CDC], 2016). Both the fall rate and the number of fall injuries also increase with age, with about $37 \%$ of adults aged 75 and older experiencing a fall, and about $13.5 \%$ of adults in this age group experiencing a fall injury each year (Bergen, Stevens, \& Burns, 2016). Falls are associated with high morbidity, low quality of life, unnecessary hospitalisation, increased financial burdens and high mortality (Peel, 2011). Fractures and traumatic injuries to the brain or internal organs are common after falls, and these can lead to further complications, such as haemorrhagic shock, sepsis, subdural haematomas and death (Chechik et al., 2012; Gazibara et al., 2014; Nahm, Como, Wilber, \& Vallier, 2011). Among older people, fall-related fractures can reduce health-related quality of life substantially, as compared with the period before the fractures occurred (González et al., 2014). Falls account for over $80 \%$ of both injury-related hospital admissions and deaths for older people in the United States (CDC, 2012), and more time spent in the hospital is also associated with higher health care costs ( $\mathrm{Nahm}$ et al., 2011). In the United States, for example, the average cost of fall-related health care is around US $\$ 10,000$ per Medicare beneficiary per year; this figure is doubled for adults 72 and older (CDC, 2016). There is thus a clear and urgent need to prevent falls in older people, from both the individual and societal points of view.

Many different factors are associated with falls among community-dwelling older people. Although cognitive impairments are a well-known risk factor for falls in older people (Muir, Gopaul, \& Montero Odasso, 2012), steps can be taken to reduce this risk. For instance, improving their environmental quality can significantly decrease the risk of falls in older people with cognitive impairments (Eshkoor, Hamid, Nudin, \& Mun, 2014). In addition, functional impairment is associated with a fear of falling, which both increases the risk of falling and worsens fall-related outcomes (Brustio, Magistro, Zecca, Liubicich, \& Rabaglietti, 2018; Gazibara et al., 2014; Mamikonian-Zarpas \& Laganá, 2015). In systemic reviews, the most vulnerable groups of fall risk include older people with either cognitive impairments, functional impairments or both (Fernando, Fraser, Hendriksen, Kim, \& Muir-Hunter, 2017; Härlein, Dassen, Halfens, \& Heinze, 2009). It is therefore essential to consider the various fallrisk factors when seeking to prevent falls and assist older people (Ambrose, Paul, \& Hausdorff, 2013). Unfortunately, the traditional fall-risk assessment measures are difficult to be applied to older people with cognitive impairments, as these individuals tend to be quite frail and can thus have difficulty completing the physical performance tests or self-reporting instruments (Shimada et al., 2011),

\section{What does this research add to existing knowledge in gerontology?}

- Half of our older people with cognitive impairments now live in modified home environments; a higher rate than those reported in the past.

- The hours spent caregiving and older people's functional impairments in terms of ADLs, including IADLs, differed significantly according to whether the home had been modified.

- Caregivers' information needs are critical in mediating the association between older people's impaired ADLs and home modifications for older people with cognitive impairments.

\section{What are the implications of this new knowledge for nursing care with older people?}

- Nursing care for older people with cognitive impairments must focus on the care recipients' ADLs; this may include undertaking home modifications for fall prevention.

- Nurses and other healthcare professionals should pay attention to informal caregivers' information needs and should offer them appropriate information about potentially useful home modifications.

\section{How could the findings be used to influence policy or practice or research or education?}

- The findings could contribute to improving nursing assessments by identifying the candidates most likely to benefit by preventing falls among older people with cognitive and functional impairments.

- The findings could be used in multidisciplinary programmes to provide those who care for older people with evidence-based guidelines to help prevent falls.

- Based on the findings, multidisciplinary organisations should provide standardised information on this topic and develop regulations to guide the appropriate modification of homes to prevent falls.

so more extensive supplementary data or proxy reports are needed to perform accurate evaluations of fall risk.

Informal caregivers play an important role in the provision of a wide range of information regarding fall risks for older people. Researchers have shown that caregivers are able to subjectively 
identify which older people are at high risk for both falls (Ryan, McCann, \& McKenna, 2009) and fall-associated injuries (Lach, Krampe, \& Phongphanngam, 2011; Shimada et al., 2011). Family caregivers can provide unique perspectives regarding the physical, spatial and interpersonal issues related to home safety, many of which differ from those of their care recipients (Tong, Sims-Gould, \& Martin-Matthews, 2016). Informal caregivers such as family members can encourage older people to participate in preventive interventions or to use external resources (Boltz, 2012; Lach et al., 2011; Marquardt et al., 2011; Suttanon, Hill, Said, Byrne, \& Dodd, 2012). With their caregivers' support, older people are thus more likely to seek external resources regarding home modifications that promote home safety (Marquardt et al., 2011).

Such safety-related home modifications have proven to be very effective and are the preferred strategy for fall prevention, especially for frail older people who live in the community (Chase, Mann, Wasek, \& Arbesman, 2012; Lach et al., 2011; Stark, Keglovits, Arbesman, \& Lieberman, 2017). Both older people and their informal caregivers invariably consider the home to be the preferred care setting, as this generally allows care recipients to receive the benefits of home care in a safe environment (Tong et al., 2016). Healthcare professionals, including nurses, can work with informal caregivers to encourage appropriate home modifications by educating older people; this can include information on external resources from the federal government (e.g., the Department of Veterans Affairs) and from local ageing-related services (Currin, Comans, Heathcote, \& Haines, 2012; Szanton et al., 2014). Certain types of home modifications can decrease older people's fall risks substantially, including the removal of home environmental hazards such as loose rugs and clutter and simple modifications such as the installation of bathroom grab bars, stairway railings and additional lighting (Chase et al., 2012; Enderlin et al., 2015).

Despite the fact that home modifications are effective interventions for fall prevention among older people, they are often not implemented due to a lack of knowledge and/or resources on this topic among the older people concerned (Marquardt et al., 2011). There is also limited information that focuses specifically on how caregivers' perceptions of fall risk are associated with the caregivers' information needs and home modifications (Lach et al., 2011) for older people with cognitive impairments. This gap in the literature is significant because caregivers play an essential role in fall-risk assessment and related interventions for older people with cognitive and functional impairments (Wilkinson et al., 2018). This study was therefore performed to (a) quantify the prevalence of home modifications for older people with cognitive impairments; (b) identify the sociodemographic and caregiving-related characteristics associated with the home modifications; and (c) examine how caregivers' information needs and perceptions of fall risk are associated with home modifications that support home health care and informal caregiving.

\section{2 | METHODS}

\section{1 | Design}

This study was cross-sectional and correlational in design. This secondary data analysis was based on data collected by the large 2015 National Alliance for Caregiving (NAC) and American Association of Retired Persons (AARP) survey (NAC \& AARP Public Policy Institute, 2015a, 2015b).

\section{2 | Conceptual framework}

This research project used the Andersen and Newman framework of health services utilisation (Andersen \& Newman, 1973). Figure 1 shows how this conceptual framework was used to select variables, structure mediation models and interpret the study's findings. The primary focus of the study was on population characteristics and health behaviours.

In this model, predisposing, enabling and need factors are all associated with health behaviours, although the enabling and need factors could mediate the associations among these variables. Sociodemographic characteristics and health-related conditions (e.g., cognitive and functional impairments) are considered predisposing characteristics because they exist prior to the healthcare needs or the subsequent use of health services. Caregiving-related characteristics are enabling factors because they are the result of informal caregiving on behalf of older people with cognitive

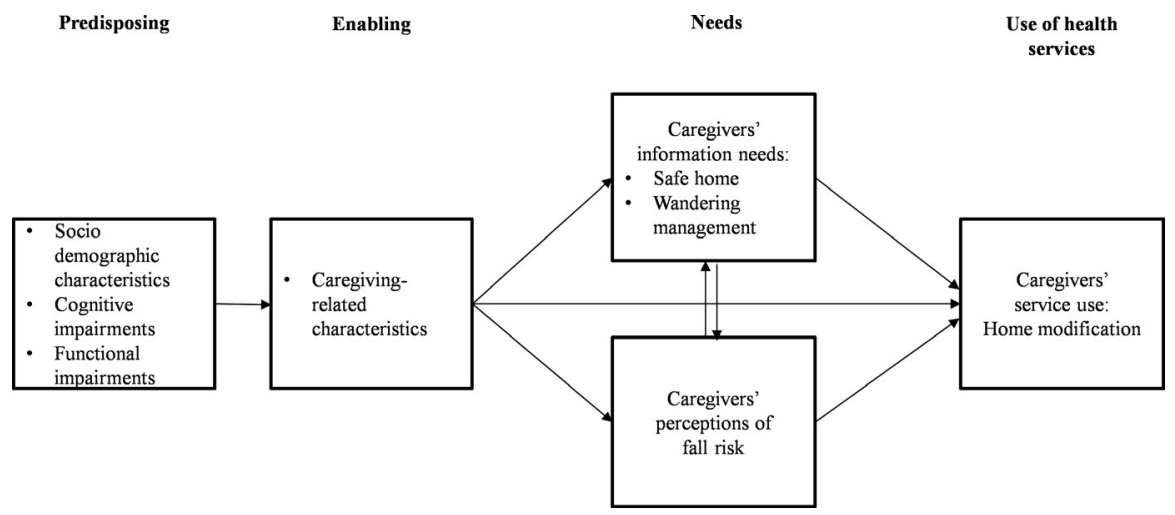

FIGURE 1 Conceptual framework for the study 
impairment. Caregivers' information needs and perceptions of fall risk are need factors because they generate a need for health services to keep the older people safe at home.

Finally, home modification is considered a status after using health services, as it promotes older people's health and well-being (Kim, Ahn, Steinhoff, \& Lee, 2014). Based on the guidelines for clinical practice provided by the American Geriatrics Society and British Geriatrics Society's Panel on Prevention of Falls in Older Persons (2010), modification of the home environment is a multifactorial fall intervention. Screening the home environment and identifying the need for modifications (with the help of healthcare professionals) is an effective intervention in the treatment of people with fall-risk factors (Panel on Prevention of Falls in Older Persons, 2011). Nurses and other healthcare providers use these practical recommendations to provide guidance regarding fall prevention (Reuben et al., 2017).

\section{3 | Data source}

This study's primary data consist of information collected for the NAC and AARP's survey of caregiving in the United States (2015b), which includes responses from 7,660 community-dwelling adults across the country. This survey was conducted from September to November 2014 and released for research use in 2015. The NAC and AARP data were gathered from GfK's national, probability-based online KnowledgePanel ${ }^{\circledR}$. Only caregivers completed the primary NAC and AARP survey; the care recipients did not. For this survey, a caregiver was defined as an individual who provides unpaid care or assistance to a family member, friend or anyone else whom the respondent knows; this includes help with personal needs or household chores (NAC \& AARP Public Policy Institute, 2015b). Thus, the person who was defined as a caregiver reported all the information for both the care recipients and themselves. To generate representative caregiver samples for the U.S. population, the NAC and AARP conducted probability sampling in the general population and targeted particular subgroups for oversampling, including racial or ethnic minorities (such as African Americans, Hispanics, and Asian Americans) and people aged 65 or older (NAC \& AARP Public Policy Institute, 2015a). The NAC and AARP selected these samples through random-digit dialling, stratified by geographic population density; this produced a set of telephone numbers and residential addresses. One caregiver was randomly selected from each household as a survey participant (NAC \& AARP Public Policy Institute, 2015b).

The NAC and AARP online survey was conducted using the computer-aided, standardised interviewing system included in KnowledgePanel ${ }^{\circledR}$. Greenwald \& Associates helped to manage the data quality as a cooperating organisation. The online questionnaire used by the NAC and AARP in 2015 was an improved version of the surveys that the same organisations used in 1997, 2004 and 2009, which were telephone-based. Caregivers (not care recipients) were asked to answer the standardised survey, which was available in either Spanish or English. The online interviews included separate sections for each of the research goals: (a) sociodemographic and health-related characteristics of both caregivers and care recipients and (b) a core of interviews about caregiving. After providing informed consent, the caregivers received unique logins that allowed them to access the online surveys; they used their own equipment to do so. For caregivers who had no Internet access, GfK provided a laptop with an Internet connection free of charge (NAC \& AARP Public Policy Institute, 2015b).

\subsection{Study samples for the secondary data analysis}

This secondary data analysis used a subsample of 226 informal caregivers among the 1,563 caregivers in the larger survey. The inclusion criteria were informal caregivers who were caring for older people with cognitive impairments such as Alzheimer's disease (Figure 2). The care recipients were defined as older if they were at least 60 years old. Care recipients not receiving informal caregiving, such as no or paid caregivers, were excluded in the analysis. The final sample size was 226 , thus satisfying the requirements for the structural equation modelling (SEM)-10 to 20 subjects for every free parameter, as well as at least 200 in total (Fritz \& MacKinnon, 2007; MacKinnon, 2008).

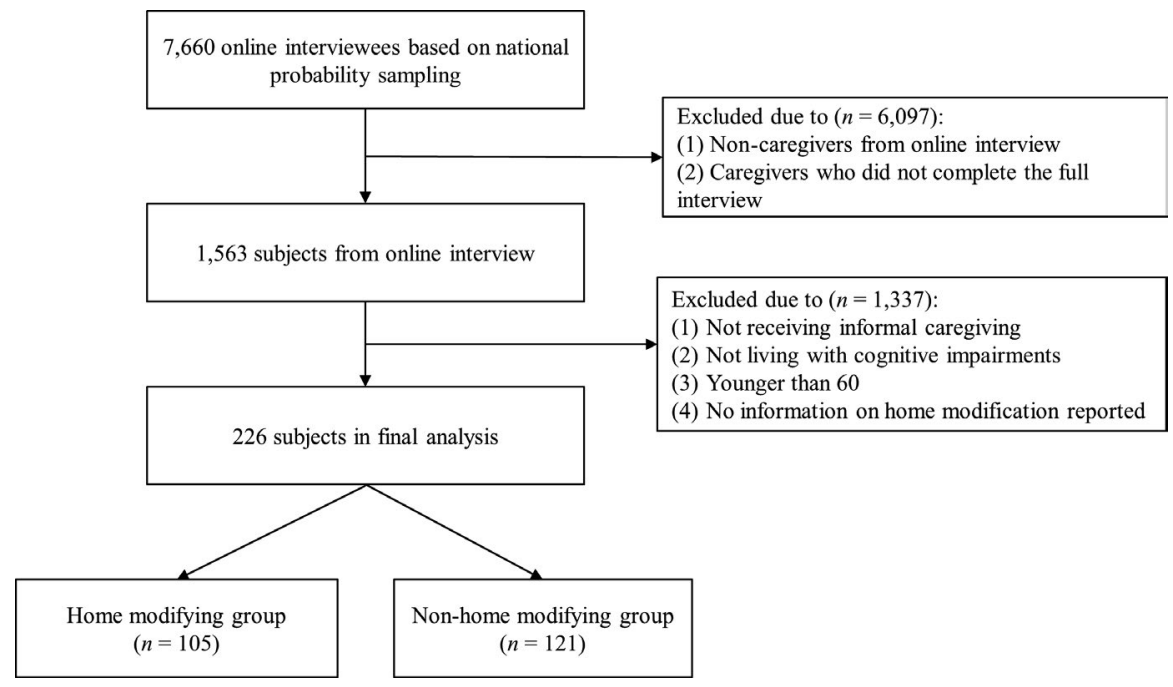

FIGURE 2 Flowchart of the study 


\section{5 | Variables and measurements}

\subsection{1 | Home modifications}

Consistent with the method used in previous studies (Kim et al., 2014; Marquardt et al., 2011; The Scan Foundation, 2010), home modification was identified through the caregiver reporting question, "Have modifications been made in the house or apartment where your (care recipient) lives/lived to make things easier for him/ her?" The caregiver's response was dichotomised, with "Yes" coded as 1 and "No" coded as 0 to indicate the referent groups.

\subsection{2 | Characteristics of older people}

Based on our conceptual framework and the literature review, we included several types of sociodemographic data for the older people that may be associated with home modifications (Kim et al., 2014; Lord, Menz, \& Sherrington, 2006). The older people's ages, sex, living arrangements, residential areas and household incomes were examined, with their age being a continuous variable and the other information categorical variables. We coded these reference groups as 0: male, living with others, urban residential area and annual household income of less than US\$50,000.

We evaluated the functional impairment of the older people with cognitive impairments based on their ADLs, including instrumental ADLs (IADLs), which were again based on the caregivers' reports. The variables for ADLs were based on Katz's scales (Katz, Ford, Moskowitz, Jackson, \& Jaffe, 1963), and the variables for the IADLs were based on Lawton and Brody's scales (Lawton \& Brody, 1969). These two instruments have been widely used for older people via self-reports; proxy, caregiver or informant reports; and professional observations (Mlinac \& Feng, 2016). We used counting variables for impaired ADLs and IADLs (range: 0-6), with higher scores indicating that the older people were more dependent on assistance from their caregivers for ADLs (Cronbach's alpha $=0.808$ ) and IADLs (Cronbach's alpha $=0.762$ ).

\subsection{3 | Caregiving-related characteristics}

The caregiving-related characteristics reflect the older people's conditions that require informal caregiving. This study data include the duration spent caregiving, as well as the caregivers' information needs and their perceived risks of falling, each of which is a significant contributor to the caregiver burden (Chiao, Wu, \& Hsiao, 2015).

In the survey, the history of caregiving comprised two continuous caregiver-reported variables: weekly hours spent caregiving and years of caregiving. The weekly hours spent on caregiving ranged from 1 (less than $60 \mathrm{~min}$ or one hour) to 168 (constant care). The years of caregiving constituted the length of time in the caregiver role. Caregivers with 1 year or less in this role were coded as 1 ; higher values represent the number of years spent providing such care.

We measured information needs using two items: (a) seeking information for keeping the care recipient safe at home and (b) seeking information for wandering management. A factor score was then constructed from these two variables based on a confirmatory factor analysis. The caregivers self-reported their perceptions of their care recipients' fall risks. Caregivers who perceived that the older people's main problem was a feeble condition, unsteady gait, history of previous falls or mobility difficulty were classified as belonging to the "risk" group (coded as 1). The others were classified in the "no-risk" group (coded as 0).

\section{6 | Data analysis}

We performed independent $t$ tests, Mann-Whitney $U$ tests and chisquare statistics, as well as a hierarchical binary logistic regression analysis, using the Statistical Package for the Social Sciences Amos (version 23.0). SEM was also utilised to complete a mediation analysis. The two-tailed level of significance was set at 0.05. We did not apply either household or individual weights because the NAC and AARP did not calculate these based on the care recipients' characteristics (NAC \& AARP Public Policy Institute, 2015b).

In the regression analysis, the blocks were as follows: Block 1 consisted of the older people's functional impairment based on ADLs and IADLs; Block 2 covered the caregiving-related characteristics; and Block 3 comprised the caregivers' information needs and their perceptions of fall risks. Prior to each analysis, we checked all the pertinent assumptions, including multicollinearity and both univariate and multivariate normalities. To correct for univariate normality, we transformed the variables of weekly caregiving hours and years of caregiving using a natural log function. For multivariate normality, we identified no outliers.

After excluding the non-significant variables, we conducted an SEM for mediation analysis. The model consisted of the older people's ADLs (the independent variable), home modifications (the dependent variable) and two mediators (caregivers' information needs and perceptions of fall risk). We controlled for age because it is spurious to associate them with all the variables in the model. The hypothesised mediation models were tested in accordance with MacKinnon's (2008) recommendations, using a bias-corrected bootstrap sampling distribution. Bias-corrected bootstrapping is helpful as it permits researchers to test hypotheses more accurately than conventional methods (Fritz \& MacKinnon, 2007; Levy, Landerman, \& Davis, 2011). Bias-corrected bootstrapping utilises repeated random sampling from the original samples. A bias-corrected confidence interval of $95 \%$ was applied here based on 5,000 bootstrap estimates, as well as bootstrap maximum likelihood (MacKinnon, 2008). The model-fit indices used for this evaluation were the chi-square statistic, comparative fit index, normed fit index, root mean square error of approximation (and its associated $90 \%$ confidence interval) and the Akaike information criterion (MacKinnon, 2008).

\subsection{Ethical considerations}

For the primary data in the NAC and AARP survey, all participating caregivers were anonymous volunteers who provided written, informed consent; the resulting NAC and AARP data is free for public 
use. The data provided does not include identifying or other personal information and hence poses only a minimal risk to confidentiality and the privacy of the caregivers. Prior to this secondary data analysis, we confirmed the data's exempt status through the Institutional Review Board of the affiliated university. There was no direct relationship between the caregivers and the researchers in this study.

\section{3 | RESULTS}

\section{1 | Description of older people with cognitive impairments}

Table 1 shows the sociodemographic and caregiving-related characteristics of the older people with cognitive impairments. Their average age was 82.65 years $(S D=8.40)$. The majority were female (66.8\%), resided with others (80.9\%) and lived in urban areas (74.4\%); most $(64.1 \%)$ had an annual household income of US\$50,000 or more. According to their caregivers, the older people with cognitive impairment received informal caregiving for a mean of $29.25 \mathrm{hr}$ per week $(S D=31.14)$ and had been receiving care from their caregiver for a mean of 5.01 years $(S D=7.15)$. On average, the caregivers reported $1.82(S D=1.97)$ functional $A D L$ impairments in their care recipients and $4.22(S D=1.82)$ IADL impairments. The caregivers indicated a need for information on how to make the home environment safer (45.1\%) and on the management of wandering care recipients (34.1\%) to help them deal with these functional impairments. The majority of the caregivers perceived that their care recipients were at some risk of falls (89.8\%).

\subsection{Group comparison of characteristics by home modification}

Among those caring for older people with cognitive impairments, $46.5 \%$ reported that the care recipients' homes had been modified to

TAB LE 1 Sociodemographic and caregiving-related characteristics of the older people living with cognitive impairments

\begin{tabular}{|c|c|c|c|c|}
\hline & All & $\begin{array}{l}\text { Home modification group } \\
(n=105,46.5 \%)\end{array}$ & $\begin{array}{l}\text { Non-home modification group } \\
(n=121,53.5 \%)\end{array}$ & $p$ values \\
\hline Age, mean (SD) & $82.65(8.40)$ & $83.03(8.41)$ & $82.32(8.41)$ & 0.530 \\
\hline $\begin{array}{l}\text { Weekly hours for caregiving, mean } \\
(S D)^{a}\end{array}$ & $29.25(31.14)$ & $37.19(32.67)$ & $22.55(28.23)$ & $<0.001$ \\
\hline Years of caregiving, mean $(S D)^{a}$ & $5.01(7.15)$ & $5.60(8.37)$ & $4.50(5.88)$ & 0.228 \\
\hline Impaired ADLs, mean $(S D)^{a}$ & $1.82(1.97)$ & $2.45(2.08)$ & $1.27(1.70)$ & $<0.001$ \\
\hline Impaired IADLs, mean $(S D)^{a}$ & $4.22(1.82)$ & $4.67(1.64)$ & $3.83(1.88)$ & 0.001 \\
\hline \multicolumn{5}{|l|}{ Sex, $n(\%)$} \\
\hline Male & $75(33.2)$ & $32(30.5)$ & $43(35.5)$ & \multirow[t]{2}{*}{0.420} \\
\hline Female & $151(66.8)$ & $73(69.5)$ & $78(64.5)$ & \\
\hline \multicolumn{5}{|l|}{ Living arrangement, $n(\%)$} \\
\hline Living with others & $182(80.9)$ & $89(84.8)$ & $93(77.5)$ & \multirow[t]{2}{*}{0.167} \\
\hline Living alone & $43(19.1)$ & $16(15.2)$ & $27(22.5)$ & \\
\hline \multicolumn{5}{|l|}{ Type of residential area, $n(\%)$} \\
\hline Urban & $160(74.4)$ & $72(72.7)$ & $88(75.9)$ & \multirow[t]{2}{*}{0.600} \\
\hline Rural & $55(25.6)$ & $27(27.3)$ & $28(24.1)$ & \\
\hline \multicolumn{5}{|l|}{ Household income, $n$ (\%) } \\
\hline Above US\$50,000 & $143(64.1)$ & $63(61.8)$ & $80(66.1)$ & \multirow[t]{2}{*}{0.500} \\
\hline Below US\$50,000 & $80(35.9)$ & $39(38.2)$ & $41(33.9)$ & \\
\hline \multicolumn{5}{|c|}{ Need for information on safer homes, $n(\%)$} \\
\hline Expressed & $102(45.1)$ & $57(54.3)$ & $45(37.2)$ & \multirow[t]{2}{*}{0.010} \\
\hline Not expressed & $124(54.9)$ & $48(45.7)$ & $76(62.8)$ & \\
\hline \multicolumn{5}{|c|}{ Need for information on wandering management, $n(\%)$} \\
\hline Expressed & $77(34.1)$ & $44(41.9)$ & $33(27.3)$ & \multirow[t]{2}{*}{0.021} \\
\hline Not expressed & $149(65.9)$ & $61(58.1)$ & $88(72.7)$ & \\
\hline \multicolumn{5}{|c|}{ Caregivers' perceptions of fall risk, $n(\%)$} \\
\hline Risk & $203(89.8)$ & $89(84.8)$ & $114(94.2)$ & \multirow[t]{2}{*}{0.019} \\
\hline No risk & $23(10.2)$ & $16(15.2)$ & $7(5.8)$ & \\
\hline
\end{tabular}

Note: ADLs, activities for daily living; IADLs, instrumental activities for daily living; SD, standard deviation.

${ }^{a}$ Tested by non-parametric test. 
support their care. There was a significant difference in the amount of care needed based on whether the caregivers had modified the care recipients' homes. In the home-modification group, the older people required more hours of caregiving each week $(p<0.001)$ and the older people with cognitive impairment had more functional impairments in their ADLs and IADLs $(p \leq 0.001)$. The caregivers in the home-modification group also expressed a greater need for information on making their homes safe $(p=0.010)$ and managing their care recipients' wandering ( $p=0.021)$ than caregivers who had not modified their homes, while caregivers who had not modified their homes perceived a higher level of fall risk than those in the homemodification group $(p=0.019)$. There were no statistical differences between the two groups in terms of age, sex, years of caregiving, living arrangement, residential area or household income (Table 1).

\section{3 | Results of the hierarchical binary logistic regression}

The hierarchical binary logistic regression explained 15.6\% (per Cox and Snell $R^{2}$ ) or $20.9 \%$ (per Nagelkerke $R^{2}$ ) of the variance in whether the homes were modified for older people with cognitive impairments $(p<0.001)$. In the model, older people's impaired ADLs, caregivers' information needs and their perceptions of fall risk were all statistically significant factors, $\chi^{2}(6)=37.946, p<0.001$. The caregivers reported home modifications when the older people had more ADL impairment, with Wald's $\chi^{2}=6.587, p=0.010$, odds ratio $(\mathrm{OR})=1.238$ and a $95 \%$ confidence interval $(\mathrm{Cl})$ for $\mathrm{OR}=1.052-1.457$. Caregivers had a greater need for information on how to make their homes safe or on how to cope with wandering, with Wald's $\chi^{2}=6.070, p=0.014$, and $\mathrm{OR}=1.472$, with a $95 \%$
$\mathrm{Cl}$ of 1.082-2.002, and this was also the case when the caregivers perceived that the older people were feeble and thus at a greater risk of falls, with Wald's $\chi^{2}=4.049, p=0.044$, and OR $=2.877$, with a $95 \%$ $\mathrm{Cl}$ of 1.028-8.052. However, IADL impairments, weekly hours spent caregiving, and years of caregiving did not have significant associations with home modification (Table 2).

\subsection{Results of mediation analyses with structural equation modelling}

Prior to completing the SEM, a correlation matrix was identified based on the significant variables obtained from the logistic regression (Table 3). The four competing models were Model 1, a multiple-mediator model with a recursive relationship between the two mediators (caregivers' information needs and perceptions of fall risk); Models 2 and 3, multiple-mediator models with one-way relationships between the two mediators; and Model 4, a multiplemediator model with no relationship between the two mediators. A summary of the fit comparisons is provided in Table 4 (described in more detail in Appendix 1). Based on the model-fit comparison, Model 4 was selected as the final model because it had the lowest Akaike information criterion, but the fits of all the other models were also acceptable in terms of their cutoffs and their insignificant chi-squared statistics. Model 4 achieved the following results: $\chi^{2}=0.053 ; p=0.818$; comparative fit index $=1.000$; normed fit index $=0.999$; and root mean square error of approximation $=0.001$, with a $90 \% \mathrm{Cl}$ of $0.001-0.108$.

Figure 3 shows the direct, indirect and total effects that caregivers' information needs and their perceptions of fall risk had on the significant relationship between older people's impaired ADLs

TAB LE 2 Hierarchical binary logistic regression analysis

\begin{tabular}{|c|c|c|c|c|c|c|c|c|c|}
\hline & \multirow[b]{2}{*}{ Variables } & \multirow[b]{2}{*}{ B } & \multirow[b]{2}{*}{ SE } & \multirow[b]{2}{*}{ Wald's $X^{2}$} & \multirow[b]{2}{*}{$d f$} & \multirow[b]{2}{*}{$p$} & \multirow[b]{2}{*}{ OR } & \multicolumn{2}{|c|}{$95 \% \mathrm{Cl}$ for OR } \\
\hline & & & & & & & & Lower & Upper \\
\hline & Constant & -1.348 & 0.419 & 10.325 & 1 & 0.001 & 0.260 & & \\
\hline Block 1: & $\begin{array}{l}\text { Older people's impaired } \\
\text { ADLs }\end{array}$ & 0.214 & 0.083 & 6.587 & 1 & 0.010 & 1.238 & 1.052 & 1.457 \\
\hline $\begin{array}{l}\text { Predisposing } \\
\text { factors }\end{array}$ & $\begin{array}{l}\text { Older people's impaired } \\
\text { IADLs }\end{array}$ & 0.001 & 0.113 & $<0.001$ & 1 & 0.990 & 1.001 & 0.802 & 1.251 \\
\hline Block 2: & $\begin{array}{l}\text { Weekly hours for } \\
\text { caregiving }\end{array}$ & 0.220 & 0.131 & 2.794 & 1 & 0.095 & 1.246 & 0.963 & 1.612 \\
\hline $\begin{array}{l}\text { Enabling } \\
\text { factors }\end{array}$ & Years of caregiving & 0.116 & 0.136 & 0.728 & 1 & 0.394 & 1.123 & 0.860 & 1.466 \\
\hline Block 3: & $\begin{array}{l}\text { Caregivers' information } \\
\text { needs }\end{array}$ & 0.387 & 0.157 & 6.070 & 1 & 0.014 & 1.472 & 1.082 & 2.002 \\
\hline Need factors & $\begin{array}{l}\text { Caregivers' perceptions of } \\
\text { fall risk }\end{array}$ & 1.057 & 0.525 & 4.049 & 1 & 0.044 & 2.877 & 1.028 & 8.052 \\
\hline $\begin{array}{l}\text { Cox and Snell } \\
R^{2}\end{array}$ & & & & & & $0.156^{* * *}$ & & & \\
\hline Nagelkerke $R^{2}$ & & & & & & $0.209^{* * *}$ & & & \\
\hline
\end{tabular}

Note: ADLs, activities for daily living; $\mathrm{Cl}$,confidence interval; IADLs, instrumental activities for daily living; OR, odds ratio; SE, standard error. ${ }^{* * *} p<0.001$ 


\begin{tabular}{|c|c|c|c|c|c|}
\hline Variables & 1 & 2 & 3 & 4 & 5 \\
\hline 1. Home modification & 1.00 & & & & \\
\hline $\begin{array}{l}\text { 2. Older people's impaired } \\
\text { ADLs }\end{array}$ & $0.298^{* *}$ & 1.00 & & & \\
\hline $\begin{array}{l}\text { 3. Caregivers' information } \\
\text { needs-safe home }\end{array}$ & $0.171^{* *}$ & 0.039 & 1.00 & & \\
\hline $\begin{array}{l}\text { 4. Caregivers' informa- } \\
\text { tion needs-wandering } \\
\text { management }\end{array}$ & $0.154^{*}$ & $0.176^{*}$ & 0.140 & 1.00 & \\
\hline $\begin{array}{l}\text { 5. Caregivers' perceptions of } \\
\text { fall risk }\end{array}$ & $0.156^{*}$ & 0.128 & 0.106 & -0.057 & 1.00 \\
\hline
\end{tabular}

TABLE 3 Correlation coefficients for the measured variables

Note: ADLs, activities for daily living.

${ }^{*} p<0.05$

${ }^{* *} p<0.01$.

TAB LE 4 Model-fit indices among four competing models

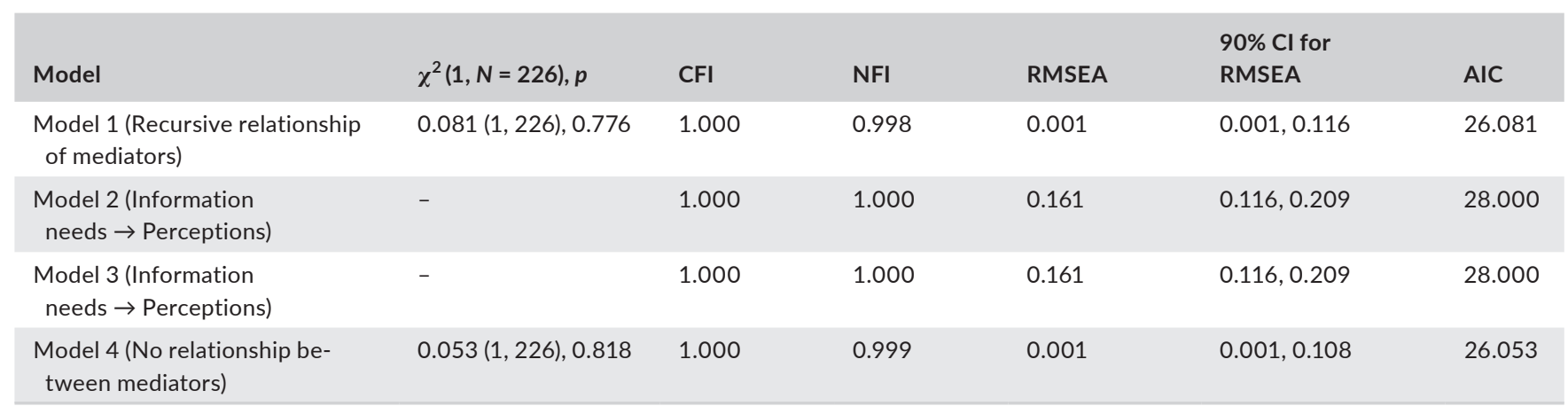

Note: AIC, Akaike information criterion; $\mathrm{CFI}$, comparative fit index; $\mathrm{Cl}$, confidence interval; NFI, normed fit index; RMSEA, root mean square error of approximation.

and home modifications. Although the caregivers' information needs partially mediated that relationship (indirect effect $=0.026$, $p<0.05$ ), the caregivers' perceptions of fall risk did not mediate that relationship due to the insignificant relationship between caregivers' perceptions and home modifications. There was no relationship between the two mediators

\section{DISCUSSION}

The aim of this study was to investigate the characteristics of older people with cognitive impairments who live in homes that have been modified, with a specific focus on their functional impairments and the mediating roles of caregivers' information needs and perceptions of fall risk. Half of the older people with cognitive impairments were living in homes that had been modified to support their needs and were receiving informal caregiving. Older people's impaired ADLs, caregivers' information needs and their perceptions of fall risk were all significantly associated with home modifications. Impaired ADLs were particularly strongly associated with home modification, although this relationship was partially mediated by the caregivers' information needs.

These findings reveal that almost half, $46.5 \%$, of the older people with cognitive impairment were living in modified home

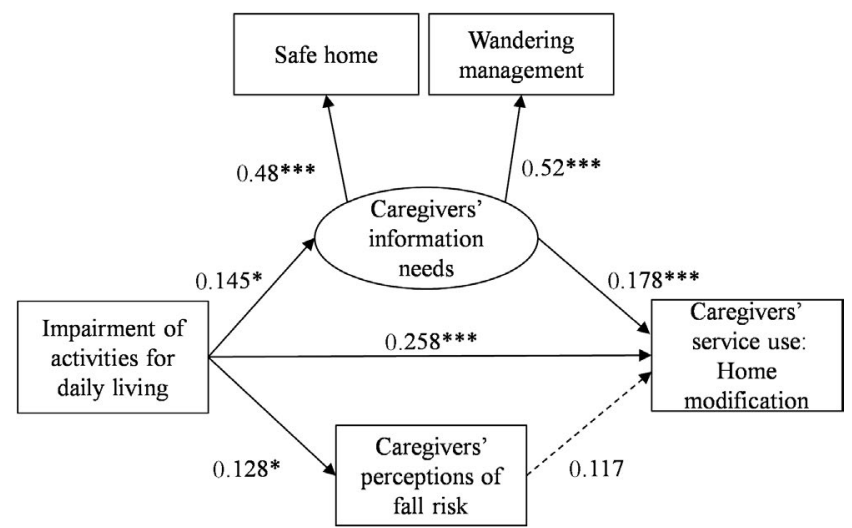

FIGURE 3 Results of the multiple-mediator model. This structural equation model illustrates the standardised regression coefficients. All path coefficients are statistically significant, except for the path from caregivers' perceptions of fall risk to home modification. A dotted line means a relationship has a statistically insignificant coefficient. ${ }^{*} p<0.05,{ }^{* *} p<0.01,{ }^{* * *} p<0.001$

environments. Combined with the findings of earlier studies (Kim et al., 2014; The Scan Foundation, 2010), this suggests a steady increase in home modifications for older people over the last decade; the reported prevalence of home modification was $36 \%$ in 2006 (The Scan 
Foundation, 2010), rising to $42.2 \%$ in 2009 (Kim et al., 2014). Home modification is an important component of a multifactor fall-preventive programme, and the American Geriatrics Society and British Geriatrics Society include it in their clinical practice guidelines for the prevention of falls among older persons (Panel on Prevention of Falls in Older Persons, 2011). Similarly, the CDC includes home modification in its guidelines for fall prevention among communitydwelling older people (CDC \& National Center for Injury Prevention $\&$ Control, 2015). This growth in home modification could indicate that older people and their families are paying more attention now than they did before to keeping their homes safe. Such modifications enable older people to stay in their homes for longer and reduce the cost and disruption incurred by moving into long-term care facilities (Joint Center for Housing Studies of Harvard University, 2013; Lach et al., 2011). This suggests that healthcare providers should be prepared to meet the increasing and diverse needs of both older people and their family members by carefully considering the benefits and daily challenges that homebound older people and their caregivers encounter in terms of concerns, risk factors, roles and responsibilities (Fjordside \& Morville, 2016; Ryan et al., 2009; Tong et al., 2016).

Older people's impaired ADLs were significantly associated with home modification, but IADLs were not. This finding is consistent with that of an earlier study on home modifications among older people, where a secondary data analysis using data from the 2011 National Health and Aging Trends Study suggested that older people who have more difficulties performing ADLs are more likely to have home modifications than those who have fewer such difficulties (Meucci, Gozalo, Dosa, \& Allen, 2016). This significant association between home modification and ADLs is not surprising, given the major effort involved in home modifications (particularly those designed to improve the bathroom environment) to better meet the needs of older people with impaired ADLs (e.g., impairments in bathing, using the toilet and transferring; Meucci et al., 2016). A great deal of research has shown that home modifications significantly improve ADL performance among older people (Chase et al., 2012; Stark et al., 2017). Those with impaired ADLs also have an above average chance of experiencing a severe cognitive impairment, so home modification is particularly advantageous for older people with impaired ADLs, at least for those for whom staying at home in the community is still possible (Stark et al., 2017).

Our assumption was that longer hours or years spent caregiving would be likely to increase the accumulated caregiver burden, which would be ameliorated by better access to external resources and coping strategies such as home modification (Chiao et al., 2015). However, our analysis found that caregiving-related information becomes non-significant when other factors such as functional impairment and information needs were taken into account. This suggests that caregiving-related characteristics are less important than increasing the use of direct resources or health care when there is a strong need related to a particular problem. We found that caregivers' information needs related to fall management were significantly associated with home modification, partially mediating the relationship between older people's impaired ADLs and home modification.
This suggests that it is crucial for nursing providers to work closely with multidisciplinary healthcare professionals such as occupational therapists, physical therapists and construction professionals to provide relevant resources and information to caregivers regarding both home modification and fall prevention (Lach et al., 2011). A multidisciplinary team plays an important role in helping caregivers understand the importance of home modification in fall prevention as part of both health care and community well-being, as caregivers are more likely to initiate home modifications after discussing their options with healthcare professionals (Marquardt et al., 2011).

Healthcare professionals can utilise clinical guidelines and online resources when providing educational information to caregivers. For example, the American Geriatrics Society and British Geriatrics Society have provided clinical practice guidelines for the prevention of falls in older persons. This programme's comprehensive approach to fall prevention in older people includes a home-environment assessment that highlights potentially helpful home modifications (Panel on Prevention of Falls in Older Persons, 2011). The CDC has also developed a checklist to identify environmental hazards in the home, providing recommendations for home-hazard reduction through home modifications (CDC \& National Center for Injury Prevention \& Control, 2015). Thus, healthcare providers should (a) be aware of the diverse sources of information that are available to help caregivers select appropriate home modifications; (b) provide specific information-based education regarding the older people's conditions and their caregivers' needs; and (c) evaluate their understanding to determine the caregivers' level of knowledge and acceptance of home modification's benefits, as well as their satisfaction with the information provided (Lach et al., 2011).

Our findings reveal that caregivers' perceptions of fall risk are significantly and independently associated with home modification. However, their perceptions did not influence home modification decisions once the older people's impaired ADLs and the caregivers' information needs were taken into account. This unexpected finding may be understandable in the context of Andersen and Newman's framework of health services utilisation (Andersen \& Newman, 1973), where a perceived need activates an immediate search for health services and for information on the options for dealing with health problems, while an evaluated need relates to professional judgement and the decision to accept healthcare assistance or resources. The informal caregivers in our study had undertaken home modifications based on their evaluated needs, using relevant information rather than subjective views or worries (Andersen \& Newman, 1973). This was because modifying the home environment is expensive and requires the caregivers' time and attention. One major barrier to home modification is that caregivers do not essentially understand when such modification becomes necessary or would be helpful for fall prevention (Marquardt et al., 2011). These misperceptions of home modification may be due to the caregivers' lack of knowledge about the methods that have been shown to be helpful for fall prevention (Pynoos, Steinman, Do Nguyen, \& Bressette, 2012). This suggests that nurses and other healthcare professionals, when providing fall prevention education to the caregivers, should focus on explaining 
how the care recipients' various conditions or symptoms could improve as a result of appropriate choice of home modifications.

\subsection{Limitations and future research}

This study has several important limitations. Firstly, as it was based on cross-sectional data, it cannot be used to infer causal relationships among older people's ADL impairment, caregivers' information needs and home modification. Based on our clinical practice, home modification tends to be decided by both the older adults and their caregivers together because of the cost implications and the complicated decision-making involved. This secondary data analysis is based on limited information concerning who initiated the process and how the decision to engage in home modification was reached. However, the findings of this study do provide useful information through its proposed associations, which could lead to fruitful research in the future that focuses on the study variables-especially with regard to longitudinal studies. Secondly, there is an inherent limitation as this secondary data analysis used survey data based on proxy reports by caregivers and questions that did not focus specifically on falls. Thus, researchers should consider adding objective measures of caregiver behaviour and/or home-environment assessments in future studies in order to examine the actual actions that caregivers routinely take to prevent falls. More specific assessment tools must also be developed to capture the specific needs of those who care for older people with cognitive impairments. Thirdly, caregivers can have different levels and types of information related to fall-risk assessment. Researchers should provide standardised sets of information on this topic in order to properly evaluate the caregivers' knowledge, practices and attitudes within controlled designs, as this could help to identify subgroups who need particular attention and assistance from healthcare providers (Chippendale \& Raveis, 2017).

\section{5 | CONCLUSION}

Overall, almost half of older people with cognitive impairments are living in homes that have been modified to support their needs. Our findings confirm that home modification is common for older people with cognitive impairments and/or limited ADLs. Our analysis indicates that caregivers' information needs (for topics such as home safety and the management of wandering older people) mediate the relationship between older people's impaired ADLs and home modification. This study's results highlight the important role healthcare professionals play in the development of high-quality, standardised, information-based education programmes targeted at caregivers. Our results also emphasise the need to identify hazards in the home environment, particularly for older people with impaired ADLs. If we are to raise the standard of the care provided to older people with cognitive impairments living in the community, more research is needed to differentiate caregivers' knowledge, practices and attitudes regarding appropriate home modifications.

\section{CONFLICTS OF INTEREST}

None of the authors have any personal or financial conflicts of interest to declare.

\section{AUTHOR CONTRIBUTIONS}

The authors' responsibilities were as follows: H. K., Y. Z. and Y. H. A. designed the research; H. K. and Y. Z. performed the data acquisition; H. K., N. K. and Y. H. A. analysed and interpreted study findings; all of four authors prepared writing the manuscript; Y. H. A. had the primary responsibility for supervising all processes of study conduct and manuscript development.

\section{Implication Practice}

- Healthcare providers should be prepared to meet the needs that homebound older people with limited ADLs and their caregivers encounter challenges to prevent fall in community.

- It is crucial for nursing providers to work closely with multidisciplinary healthcare professionals to provide relevant resources and information to caregivers regarding both home modification and fall prevention.

- Healthcare professionals should focus on explaining how the care recipients' various conditions or symptoms could improve as a result of appropriate choice of home modifications.

\section{ORCID}

Heejung Kim (iD https://orcid.org/0000-0003-3719-0111

Yunchuan (Lucy) Zhao iD https://orcid.org/0000-0001-5737-1177

Namhee Kim (iD https://orcid.org/0000-0002-2862-2691

Yong Han Ahn iD https://orcid.org/0000-0002-5542-7314

\section{REFERENCES}

Ambrose, A. F., Paul, G., \& Hausdorff, J. M. (2013). Risk factors for falls among older adults: A review of the literature. Maturitas, 75(1), 5161. https://doi.org/10.1016/j.maturitas.2013.02.009

Andersen, R., \& Newman, J. F. (1973). Societal and individual determinants of medical care utilization in the United States. The Milbank Memorial Fund Quarterly. Health and Society, 51(1), 95-124. https:// doi.org/10.2307/3349613

Bergen, G., Stevens, M. R., \& Burns, E. R. (2016). Falls and fall injuries among adults aged $\geq 65$ years - United States, 2014. Morbidity and Mortality Weekly Report (MMWR), 65(37), 993-998. https://doi. org/10.15585/mmwr.mm6537a2

Boltz, M. (2012). The family caregiver: An untapped resource. Geriatric Nursing, 33(2), 137-139. https://doi.org/10.1016/j.gerin urse.2012.02.004

Brustio, P. R., Magistro, D., Zecca, M., Liubicich, M. E., \& Rabaglietti, E. (2018). Fear of falling and activities of daily living function: Mediation 
effect of dual-task ability. Aging and Mental Health, 22(6), 856-861. https://doi.org/10.1080/13607863.2017.1318257

Centers for Disease Control and Prevention [CDC] \& National Center for Injury Prevention and Control, (2015). Check for safety: A home fall prevention checklist for older adult. Retrieved from https://www. cdc.gov/steadi/pdf/check_for_safety_brochure-a.pdf.

Centers for Disease Control and Prevention [CDC], (2012). Ten leading causes of injury death by age group highlighting violence-related injury deaths, United States - 2010. Retrieved from http://www. cdc.gov/injury/wisqars/pdf/10LCID_Violence_Related_Injury_ Deaths_2010-a.pdf.

Centers for Disease Control and Prevention [CDC], (2016). Cost of falls among older adults. Retrieved from http://www.cdc.gov/homea ndrecreationalsafety/falls/fallcost.html.

Chase, C. A., Mann, K., Wasek, S., \& Arbesman, M. (2012). Systematic review of the effect of home modification and fall prevention programs on falls and the performance of community-dwelling older adults. American Journal of Occupational Therapy, 66(3), 284-291. https:// doi.org/10.5014/ajot.2012.005017

Chechik, O., Amar, E., Khashan, M., Kadar, A., Rosenblatt, Y., \& Maman, E. (2012). In support of early surgery for hip fractures sustained by elderly patients taking clopidogrel. Drugs and Aging, 29(1), 63-68. https://doi.org/10.2165/11598490-000000000-00000

Chiao, C. Y., Wu, H. S., \& Hsiao, C. T. (2015). Caregiver burden for informal caregivers of patients with dementia: A systematic review. International Nursing Review, 62(3), 340-350. https://doi. org/10.1111/inr.12194

Chippendale, T., \& Raveis, V. (2017). Knowledge, behavioral practices, and experiences of outdoor fallers: Implications for prevention programs. Archives of Gerontology and Geriatrics, 72, 19-24. https://doi. org/10.1016/j.archger.2017.04.008

Currin, M.L., Comans, T. A., Heathcote, K., \& Haines, T.P. (2012).Staying safe at home. Home environmental audit recommendations and uptake in an older population at high risk of falling. Australasian Journal on Ageing, 31(2), 90-95. https://doi.org/10.1111/j.1741-6612.2011.00545.x

Enderlin, C., Rooker, J., Ball, S., Hippensteel, D., Alderman, J., Fisher, S. J., ... Jordan, K. (2015). Summary of factors contributing to falls in older adults and nursing implications. Geriatric Nursing, 36(5), 397-406. https://doi.org/10.1016/j.gerinurse.2015.08.006

Eshkoor, S. A., Hamid, T. A., Nudin, S. S., \& Mun, C. Y. (2014). A research on functional status, environmental conditions, and risk of falls in dementia. International Journal of Alzheimer's Disease, 2014, 769062. https://doi.org/10.1155/2014/769062

Fernando, E., Fraser, M., Hendriksen, J., Kim, C. H., \& Muir-Hunter, S. W. (2017). Risk factors associated with falls in older adults with dementia: A systematic review. Physiotherapy Canada, 69(2), 161-170. https ://doi.org/10.3138/ptc.2016-14

Fjordside, S., \& Morville, A. (2016). Factors influencing older people's experiences of participation in autonomous decisions concerning their daily care in their own homes: A review of the literature. International Journal of Older People Nursing, 11(4), 284-297. https:// doi.org/10.1111/opn.12116

Fritz, M. S., \& MacKinnon, D. P. (2007). Required sample size to detect the mediated effect. Psychological Science, 18(3), 233-239. https:// doi.org/10.1111/j.1467-9280.2007.01882.x

Gazibara, T., Pekmezovic, T., Tepavcevic, D. K., Tomic, A., Stankovic, I., Kostic, V. S., \& Svetel, M. (2014). Circumstances of falls and fall-related injuries among patients with Parkinson's disease in an outpatient setting. Geriatric Nursing, 35(5), 364-369. https://doi. org/10.1016/j.gerinurse.2014.05.001

González, N., Aguirre, U., Orive, M., Zabala, J., García-Gutiérrez, S., Las Hayas, C., ... Quintana, J. M. (2014). Health-related quality of life and functionality in elderly men and women before and after a fallrelated wrist fracture. International Journal of Clinical Practice, 68(7), 919-928. https://doi.org/10.1111/ijcp.12410
Härlein, J., Dassen, T., Halfens, R. J., \& Heinze, C. (2009). Fall risk factors in older people with dementia or cognitive impairment: A systematic review. Journal of Advanced Nursing, 65(5), 922-933. https://doi. org/10.1111/j.1365-2648.2008.04950.x

Joint Center for Housing Studies of Harvard University (2013). The US housing stock: Ready for renewal: Improving America's housing 2013. Retrieved from http://www.jchs.harvard.edu/sites/jchs.harva rd.edu/files/harvard_jchs_remodeling_report_2013.pdf.

Katz, S., Ford, A. B., Moskowitz, R. W., Jackson, B. A., \& Jaffe, M. W. (1963). Studies of illness in the aged. The index of ADL: A standardized measure of biological and psychosocial function. The. Journal of the American Medical Association, 185(12), 914-919. https://doi. org/10.1001/jama.1963.03060120024016

Kim, H., Ahn, Y. H., Steinhoff, A., \& Lee, K. H. (2014). Home modification by older adults and their informal caregivers. Archives of Gerontology and Geriatrics, 59(3), 648-656. https://doi.org/10.1016/j.archg er.2014.07.012

Lach, H. W., Krampe, J., \& Phongphanngam, S. (2011). Best practice in fall prevention: Roles of informal caregivers, health care providers and the community. International Journal of Older People Nursing, 6, 299-306. https://doi.org/10.1111/j.1748-3743.2011.00298.x

Lawton, M. P., \& Brody, E. M. (1969). Assessment of older people: Self-maintaining and instrumental activities of daily living. The Gerontologist, 9(3), 179-186. https://doi.org/10.1093/geron t/9.3_Part_1.179

Levy, J. A., Landerman, L. R., \& Davis, L. L. (2011). Advances in mediation analysis can facilitate nursing research. Nursing Research, 60(5), 333-339. https://doi.org/10.1097/NNR.0b013e318227efca

Lord, S. R., Menz, H. B., \& Sherrington, C. (2006). Home environment risk factors for falls in older people and the efficacy of home modifications. Age and Ageing, 35(Suppl. 2), ii55-ii59. doi: https://doi. org/10.1093/ageing/afl088

MacKinnon, D. P. (2008). Introduction to statistical mediation analysis. Mahwah, NJ: Erlbaum.

Mamikonian-Zarpas, A., \& Laganá, L. (2015). The relationship between older adults' risk for a future fall and difficulty performing activities of daily living. Journal of Aging and Gerontology, 3(1), 8-16. https://doi. org/10.12974/2309-6128.2015.03.01.2

Marquardt, G., Johnston, D., Black, B. S., Morrison, A., Rosenblatt, A., Lyketsos, C. G., \& Samus, Q. M. (2011). A descriptive study of home modifications for people with dementia and barriers to implementation. Journal of Housing for the Elderly, 25(3), 258-273. https://doi. org/10.1080/02763893.2011.595612

Meucci, M. R., Gozalo, P., Dosa, D., \& Allen, S. M. (2016). Variation in the presence of simple home modifications of older Americans: Findings from the National Health and Aging Trends Study. Journal of the American Geriatrics Society, 64(10), 2081-2087. https://doi. org/10.1111/jgs.14252

Mlinac, M. E., \& Feng, M. C. (2016). Assessment of activities of daily living, self-care, and independence. Archives of Clinical Neuropsychology, 31(6), 506-516. https://doi.org/10.1093/arclin/acw049

Muir, S. W., Gopaul, K., \& Montero Odasso, M. M. (2012). The role of cognitive impairment in fall risk among older adults: A systematic review and meta-analysis. Age and Ageing, 41(3), 299-308. https://doi. org/10.1093/ageing/afs012

Nahm, N. J., Como, J. J., Wilber, J. H., \& Vallier, H. A. (2011). Early appropriate care: Definitive stabilization of femoral fractures within 24 hours of injury is safe in most patients with multiple injuries. The Journal of Trauma, 71(1), 175-185. https://doi.org/10.1097/TA.0b013 e3181fc93a2

National Alliance for Caregiving and American Association of Retired Persons [NAC/AARP] Public Policy Institute. (2015a). Caregiving in the U.S. 2015 - Executive summary. Retrieved from http://www. caregiving.org/wp-content/uploads/2015/05/2015_Caregiving intheUS_Executive-Summary-June-4_WEB.pdf. 
National Alliance for Caregiving and American Association of Retired Persons [NAC/AARP] Public Policy Institute. (2015b). Caregiving in the U.S. 2015 - Appendix B: detailed methodology. Retrieved from http://www.caregiving.org/wp-content/uploads/2015/05/ CGV016-Main-Report-Appendix-B-Detailed-Methodology-5.21.15. pdf.

Panel on Prevention of Falls in Older Persons, American Geriatrics Society and British Geriatrics Society (2011). Summary of the updated American Geriatrics Society/British Geriatrics Society clinical practice guideline for prevention of falls in older persons. Journal of the American Geriatrics Society, 59(1), 148-157. https://doi. org/10.1111/j.1532-5415.2010.03234.x

Peel, N. M. (2011). Epidemiology of falls in older age. Canadian Journal on Aging, 30(1), 7-19. https://doi.org/10.1017/S071498081000070X

Pynoos, J., Steinman, B. A., Do Nguyen, A. Q., \& Bressette, M. (2012). Assessing and adapting the home environment to reduce falls and meet the changing capacity of older adults. Journal of Housing for the Elderly, 26(1-3), 137-155. https://doi.org/10.1080/02763 893.2012.673382

González, N., Aguirre, U., Orive, M., Zabala, J., García-Gutiérrez, S., Las Hayas, C., ... Quintana, J. M. (2017). The strategies to reduce injuries and develop confidence in elders intervention: Falls risk factor assessment and management, patient engagement, and nurse comanagement. Journal of the American Geriatrics Society, 65(12), 27332739. https://doi.org/10.1111/jgs.15121

Ryan, A. A., McCann, S., \& McKenna, H. (2009). Impact of community care in enabling older people with complex needs to remain at home. International Journal of Older People Nursing, 4(1), 22-32. https://doi. org/10.1111/j.1748-3743.2008.00152.x

Shimada, H., Suzukawa, M., Ishizaki, T., Kobayashi, K., Kim, H., \& Suzuki, T. (2011). Relationship between subjective fall risk assessment and falls and fall-related fractures in frail elderly people. Biomed Central Geriatrics, 11(1), 40. https://doi.org/10.1186/1471-2318-11-40

Stark, S., Keglovits, M., Arbesman, M., \& Lieberman, D. (2017). Effect of home modification interventions on the participation of community-dwelling adults with health conditions: A systematic review. American Journal of Occupational Therapy, 71(2), 7102290010p17102290010p11. https://doi.org/10.5014/ajot.2017.018887

Suttanon, P., Hill, K. D., Said, C. M., Byrne, K. N., \& Dodd, K. J. (2012). Factors influencing commencement and adherence to a home-based balance exercise program for reducing risk of falls: Perceptions of people with Alzheimer's disease and their caregivers. International Psychogeriatrics, 24(7), 1172-1182. https://doi.org/10.1017/S1041 610211002729

González, N., Aguirre, U., Orive, M., Zabala, J., García-Gutiérrez, S., Las Hayas, C., ... Quintana, J. M. (2014). CAPABLE trial: A randomized controlled trial of nurse, occupational therapist and handyman to reduce disability among older adults: Rationale and design. Contemporary Clinical Trials, 38(1), 102-112. https://doi. org/10.1016/j.cct.2014.03.005

The Scan Foundation (2010). Data brief: Home modification. Retrieved from http://www.thescanfoundation.org/home-modifications.

Tong, C. E., Sims-Gould, J., \& Martin-Matthews, A. (2016). Types and patterns of safety concerns in home care: Client and family caregiver perspectives. International Journal for Quality in Health Care, 28(2), 214-220. https://doi.org/10.1093/intqhc/mzw006

Wilkinson, A., Meikle, N., Law, P., Yong, H. J., Butler, P., Kim, J., ... Hale, L. (2018). How older adults and their informal carers prevent falls: An integrative review of the literature. International Journal of Nursing Studies, 82, 13-19. https://doi.org/10.1016/j.ijnurstu.2018.03.002

How to cite this article: Kim H, Zhao Y, Kim N, Ahn YH. Home modifications for older people with cognitive impairments: Mediation analysis of caregivers' information needs and perceptions of fall risks. Int J Older People Nurs. 2019;14:e12240. https://doi.org/10.1111/opn.12240 


\section{APPENDIX 1}

Diagrams of four competing models. The diagrams show four competing models with multiple mediators. This structural equation model illustrates the standardised regression coefficients. All path coefficients are statistically significant, except for the path represented by the dotted lines. ${ }^{*} p<0.05,{ }^{* *} p<0.01,{ }^{* * *} p<0.001$.
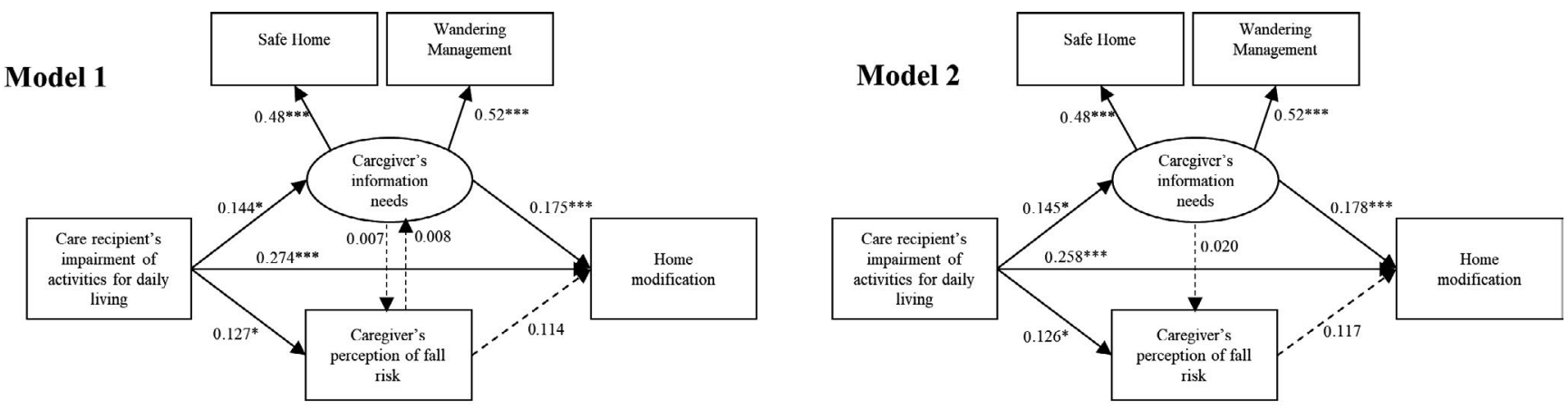

Model 3
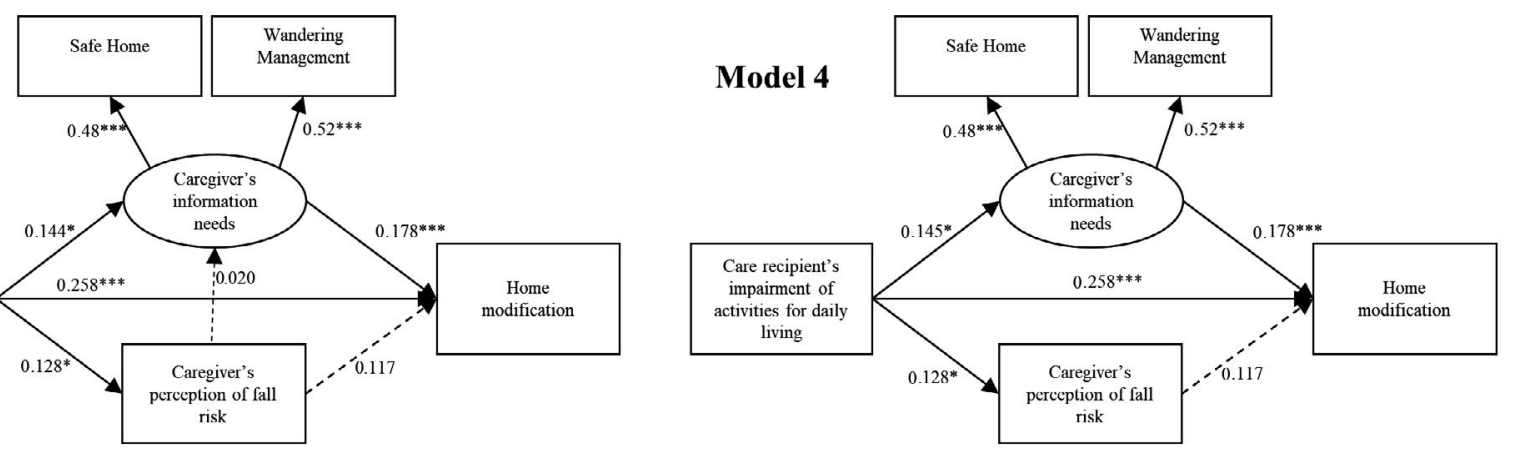

Notes: ${ }^{*} \mathrm{p}<0.05,{ }^{* *} \mathrm{p}<0.01,{ }^{* * *} \mathrm{p}<0.001 ; \rightarrow$, statistically insignificant cocfficient 